\title{
Trends and geographical patterns of pleural mesotheliomas in the Netherlands 1970-87
}

\author{
J M M Meijers, H T Planteydt, J J M Slangen, G M H Swaen, C van Vliet, F Sturmans
}

\begin{abstract}
The sex and age related trends and geographical distribution of asbestos related mortality from pleural mesothelioma in the Netherlands between 1970 and 1987 were investigated. Deaths from pleural malignancies recorded by the Dutch Central Bureau of Statistics (CBS) were used and death rates were age adjusted per year by the indirect method. Standardised mortality ratios (SMRs) were computed for 43 regions over the period 1979-86. For men, total mortality increased from 10.8 per million in the period $1970-8$ to 20.9 per million during $1979-87$. The highest mortality occurred in the group aged between 65 and 74 with $147 \cdot 7$ per million in 1987. The death rate for the group aged between 55 and 64 was 96.5 per million in 1987 . For women, total death rates for pleural mesothelioma showed a moderate increase from 2.5 per million in the period 1970-8 to 3.6 per million during 1979-87. The highest mortality occurred in the group aged over 65 , fluctuating around 10-15 per million. For men and women under $\mathbf{4 5}$ mortality was very low and presented no upward trend. The geographical distribution over the country for the period 1979-86 showed a pattern with a clear concentration of deaths from mesothelioma in men, in conurbations with many harbours, shipyards, and heavy industry near the river mouths and along the North Sea Coast.
\end{abstract}

Since the first report of an association between exposure to asbestos and diffuse pleural mesoth-

University of Limburg, Maastricht, the Netherlands, Department of Occupational and Environmental Health and Toxicology

J M M Meijers, J J M Slangen, G M H Swaen, C van Vliet Department of Epidemiology

F Sturmans

Regional Pathological Laboratory, Zeeland, Middelburg, the Netherlands

H T Planteydt elioma ${ }^{1}$ there has been a growing interest in the cause and manifestations of malignant mesothelioma (hereafter referred to as mesothelioma). It is now widely accepted that about $80 \%$ of all mesotheliomas are due to exposure to asbestos. ${ }^{2}$ The amphibole crocidolite is the main type of asbestos fibre responsible for this tumour. Mesotheliomas appear principally in the pleura, peritoneum, and occasionally in the pericardium. The prevalence of mesothelioma of the pleura is about 10 times higher than peritoneal mesothelioma. ${ }^{3}$ Mesothelioma appears to have a 30 to 40 year mean latency period and eventually it is fatal. ${ }^{4}$ The diagnosis of mesothelioma is often made by evaluating the cytological material from a pleural effusion of the tissue from an open or blind biopsy and most patients survive less than one year after diagnosis.

Although mesothelioma is still a rare tumour, the incidence of the disease has increased dramatically in many industrialised countries. This is because of the increased annual production of asbestos, from about one million to five million tonnes between 1970 and $1975 .{ }^{5}$ In countries such as Great Britain, ${ }^{6}$ South Africa, ${ }^{7}$ and Australia ${ }^{8}$ a register of mesotheliomas was set up to monitor the incidence and distribution of the disease. In other developed countries national cancer registries and the analyses of death certificates provided information about the variations in incidence of mesothelioma. ${ }^{9-11}$ The outcomes of the population based studies from various countries all indicate that the incidence of mesothelioma is still increasing in the western world; mesothelioma is diagnosed much more often in men than in women and a geographical concentration within areas with a high exposure to asbestos has been observed. ${ }^{12}$

It was not until the introduction of the 7th revision of the International Classification of Diseases (ICD) in 1958 that a separate category for pleural malignancies incorporating mesothelioma was introduced. The code 162.2 was reserved for this, but it was also possible to label a pleural mesothelioma in the category 163 ("malignant neoplasms of the lung and pleura, unspecific as to whether primary or secondary"). Starting with the 8th ICD revision in 1968, all pleural malignant mesotheliomas were to be included under 163.0 (163, ICD, 9th revision). This category comprised malignant neoplasms of the 
pleura, mediastinum, and unspecified sites. An analysis of a sample of deaths from this category has shown that about $90 \%$ of deaths in men and $70 \%$ of deaths in women from malignant neoplasms are probably due to pleural mesotheliomas. ${ }^{13}$ The other primary pleural tumour is a localised type of mesothelioma which rarely metastasises and is usually curable. As pleural mesotheliomas are fatal, mortality directly reflects incidence and is expected to reflect exposures to aetiological agents after the latency period. ${ }^{14}$ Hence the analysis of mortality from pleural malignancies has been successfully used to describe the incidence of mesotheliomas as a consequence of exposure to asbestos in populations. ${ }^{7}$

In the Netherlands cause specific death rates are accumulated through the Central Bureau of Statistics according to the latest ICD classification. Trends and geographical patterns of deaths from pleural malignancies in the Netherlands, referred to as deaths due to pleural mesothelioma, are presented in this report for the period 1970-87. A statutory mesothelioma surveillance programme does not exist in the Netherlands. Since 1969, however, an expert mesothelioma panel has invited all pathologists to send it sections of suspected diffuse malignant mesotheliomas in order to register all histologically verified cases of mesothelioma. ${ }^{15}$ The results of the mesothelioma register are compared with the outcomes of the official national death classifications.

\section{Methods}

From the Dutch Central Bureau of Statistics the absolute number of deaths due to pleural malignancies (ICD 7, 162.2; ICD 8, 163.0; ICD 9, 163) were obtained. The Netherlands are divided into 12 provinces and 43 smaller regions within these provinces. For the period 1970-8 absolute numbers of deaths were given by sex, age group, and province. For the period 1979-86, numbers of deaths were obtained for each region. For the same years total numbers of inhabitants for each region, sex, and age group were obtained. After computerisation of the data, death rates for each year, sex, and age group were produced.

To analyse the geographical distribution of the deaths from mesothelioma over the 43 regions in the period 1979-86, death rates were age adjusted separately for each year for men and women by the indirect method of standardisation. Firstly the Dutch age specific death rates from pleural mesothelioma were applied to the populations of each region for every year to calculate the expected number of deaths. Secondly, a standardised mortality ratio (SMR) was calculated and multiplied by the Dutch crude sex specific annual death rate for the eight year period. Confidence limits were calculated according to the method described by Breslow and Day. ${ }^{16}$

\section{Results}

MORTALITY BY YEAR AND AGE

Between 1958 and 1987 the crude death rate due to pleural mesotheliomas in the Netherlands had increased from 1.9 per million $(n=21)$ to 15.8 per million ( $\mathrm{n}=232)$. Table 1 presents the absolute number of deaths due to pleural mesothelioma for men and women in the Netherlands since 1970. The total number of mesotheliomas shows an almost fourfold increase from $7 \cdot 9$ per million in 1970 to $28 \cdot 1$ per million in 1987. For women, mortality increased from $2 \cdot 1$ per million to $3 \cdot 8$ per million over the same period. Thus men experienced a much stronger upward trend than women, with a man to woman ratio varying from $3 \cdot 7$ to 1 in 1970 to $7 \cdot 3$ to 1 in 1987 .

Table 2 shows the mortality from mesothelioma for the aggregated years $1970-8$ and 1979-87. The overall death rates per million for men doubled between the periods. The largest increase occurred in the group aged from 65 to 74 , followed by the group aged from 55 to 64 , and the group older than 75 . Mortality in the group aged between 45 and 54 was higher than the average mortality in the two periods, whereas the death rate from mesothelioma for men under 45 was very low and almost constant over time.

For women overall death rates were much lower than for men and increased only slightly between 1970-8 and 1979-87. In agreement with the figures for men, highest mortality occurred in the group aged between 65 and 74, followed by the women older than 75 . In the group aged under 45 mortality due to mesotheliomas was rare and reflected the normal background mortality.

Figure 1 presents trends in mortality for both sexes in the selected age groups between 1970 and 1987. The mortality for men aged between 65 and 74 showed a pattern of gradual increase from 50.6 to $147 \cdot 7$ per million. For the other age groups mesoth-

Table 1 Number of deaths from pleural mesothelioma in the Netherlands by year of death and sex of decedents

\begin{tabular}{lccc}
\hline Year of death & No of men & No of women & Total \\
\hline 1970 & 52 & 14 & 66 \\
1971 & 64 & 17 & 81 \\
1972 & 66 & 14 & 80 \\
1973 & 67 & 19 & 86 \\
1974 & 78 & 18 & 96 \\
1975 & 67 & 9 & 76 \\
1976 & 81 & 15 & 96 \\
1977 & 96 & 24 & 120 \\
1978 & 118 & 19 & 137 \\
1979 & 110 & 27 & 137 \\
1980 & 145 & 41 & 186 \\
1981 & 127 & 30 & 157 \\
1982 & 147 & 19 & 166 \\
1983 & 158 & 22 & 180 \\
1984 & 180 & 29 & 209 \\
1985 & 157 & 21 & 178 \\
1986 & 166 & 27 & 193 \\
1987 & 204 & 28 & 232 \\
\hline
\end{tabular}


Table 2 Number of deaths from and annual average death rates per million for pleural mesothelioma by age and sex during 1970-78 and 1979-87 in the Netherlands

\begin{tabular}{|c|c|c|c|c|c|c|c|c|}
\hline & \multicolumn{4}{|c|}{$1970-78$} & \multicolumn{4}{|c|}{$1979-87$} \\
\hline & \multicolumn{2}{|l|}{ Men } & \multicolumn{2}{|c|}{ Women } & \multicolumn{2}{|l|}{ Men } & \multicolumn{2}{|l|}{ Women } \\
\hline & $\begin{array}{l}\text { No of } \\
\text { deaths }\end{array}$ & $\begin{array}{l}\text { Rate per } \\
\text { million }\end{array}$ & $\begin{array}{l}\text { No of } \\
\text { deaths }\end{array}$ & $\begin{array}{l}\text { Rate per } \\
\text { million }\end{array}$ & $\begin{array}{l}\text { No of } \\
\text { deaths }\end{array}$ & $\begin{array}{l}\text { Rate per } \\
\text { million }\end{array}$ & $\begin{array}{l}\text { No of } \\
\text { deaths }\end{array}$ & $\begin{array}{l}\text { Rate per } \\
\text { million }\end{array}$ \\
\hline $\begin{array}{l}\text { All ages } \\
<45 \\
45-54 \\
55-64 \\
65-74 \\
\geqslant 75\end{array}$ & $\begin{array}{r}680 \\
25 \\
87 \\
205 \\
235 \\
128\end{array}$ & $\begin{array}{r}10.75 \\
0.58 \\
13.53 \\
39.40 \\
65.75 \\
26.34\end{array}$ & $\begin{array}{r}158 \\
5 \\
18 \\
40 \\
46 \\
49\end{array}$ & $\begin{array}{r}2.50 \\
0.12 \\
2.70 \\
6.93 \\
10.14 \\
9.09\end{array}$ & $\begin{array}{r}1394 \\
36 \\
191 \\
375 \\
469 \\
323\end{array}$ & $\begin{array}{r}20.90 \\
0.80 \\
30.36 \\
64.82 \\
118.93 \\
57.01\end{array}$ & $\begin{array}{r}244 \\
7 \\
18 \\
54 \\
76 \\
89\end{array}$ & $\begin{array}{r}3.60 \\
0.16 \\
2.63 \\
8.51 \\
14.92 \\
13.58\end{array}$ \\
\hline
\end{tabular}

elioma mortality was lower and showed a less pronounced growth. Mortality trends for the men aged between 55 and 64 increased from 33.6 per million in 1970 to 96.5 per million in 1987 . For the group aged between 45 and 54 mortality over the period rarely

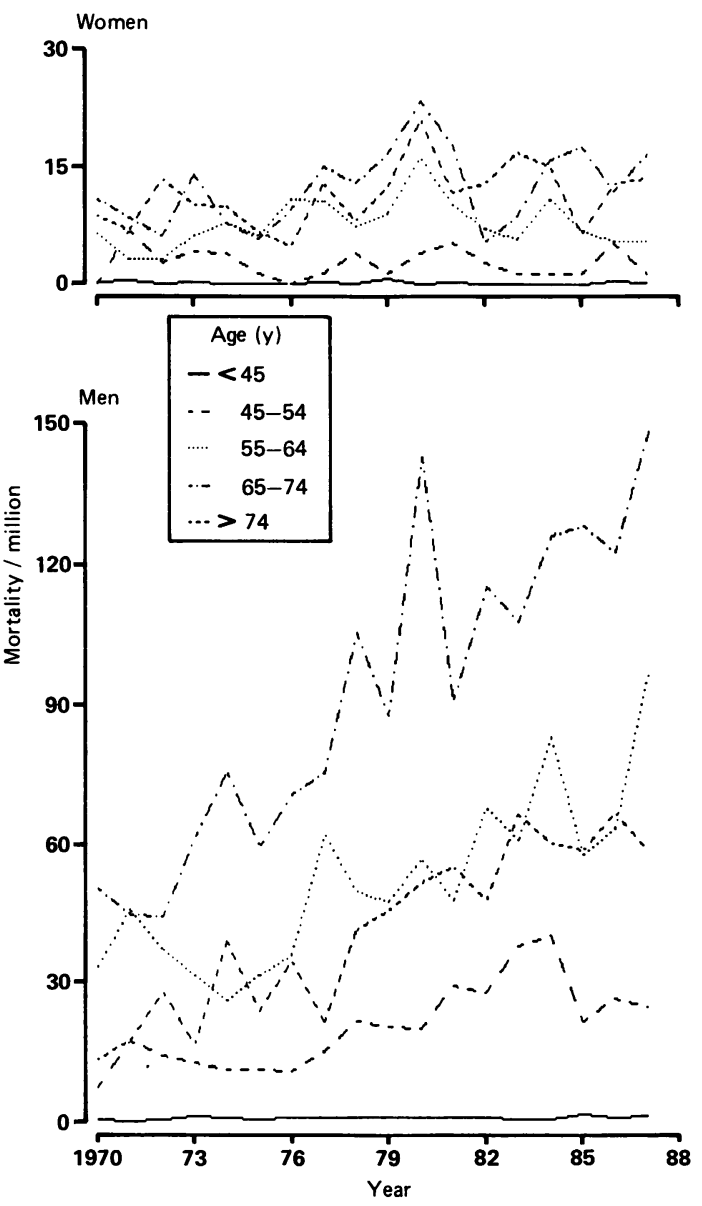

Figure 1 Mortality per million for pleural mesothelioma by age and sex in the Netherlands, 1970-87. exceeded 30 per million, and mortality for men younger than 45 was consistently low, varying between 0.22 and 1.19 per million. Compared with the same age groups in men, death rates for mesothelioma in women were much lower and only sporadically exceeded 20 per million. The highest mortality from mesothelioma occurred in those aged over 65 . The mortality for the two oldest age groups was of the same order of magnitude with only a moderate increase over time from 9-11 per million in 1970 to $14-17$ per million in 1989 . In the age groups younger than 65 mortality from mesothelioma did not show an upward trend with time. Mortality for those aged between 55 and 64 varied around six per million; for women aged between 45 and 54 from one to five per million; and for women aged under 45 years it was below 0.5 per million.

\section{MORTALITY BY REGION}

Expected numbers of deaths and SMRs were calculated over the aggregated years between 1979 and 1986 for 43 smaller regions scattered over the country. For men, the SMRs for several regions were significantly increased (table 3). The highest SMRs were observed in the mid-western regions. These regions resemble each other in many aspects. The population density is high and the regions are located near river estuaries or along the coast. Several large harbours are located in these regions. A ship building and restoring industry has developed and many other heavy industries, including petrochemical processing, refineries, and the production of steel are situated in the mid-western areas. In Rijnmond, where the harbour of Rotterdam is located, an almost threefold increase in mortality from mesothelioma occurred. In IJmond and North Sealand regions along the North Sea coast, the SMRs showed a more than twofold excess. Mortality due to pleural mesothelioma was also significantly increased in the capital city of Amsterdam and its surrounding Zaanstreek, Gooi, and Flevoland. Clearly the clusters of mortality from mesothelioma in these harbour and coastal areas are due to high occupational exposure to asbestos in the past. It is well known that workers 
Table 3 Observed (Obs) and expected (Exp) deaths and SMRs for mesothelioma of the pleura for selected regions in the Netherlands 1979-86

\begin{tabular}{|c|c|c|c|c|c|}
\hline \multirow[b]{2}{*}{ Sex } & \multirow[b]{2}{*}{ Region number } & \multirow[b]{2}{*}{ Region } & \multicolumn{2}{|c|}{ No of deaths } & \multirow[b]{2}{*}{$S M R(95 \% C I)$} \\
\hline & & & Obs & $\operatorname{Exp}$ & \\
\hline Men & $\begin{array}{r}1 \\
2 \\
3 \\
4 \\
5 \\
6 \\
7 \\
8 \\
9 \\
10\end{array}$ & $\begin{array}{l}\text { West Groningen } \\
\text { IJmond } \\
\text { Zaanstreek } \\
\text { Amsterdam City } \\
\text { Rest of Amsterdam } \\
\text { Gooi and Vecht } \\
\text { Rijnmond } \\
\text { South east South Holland } \\
\text { North Sealand } \\
\text { Flevoland }\end{array}$ & $\begin{array}{r}12 \\
32 \\
21 \\
124 \\
38 \\
35 \\
274 \\
48 \\
61 \\
13\end{array}$ & $\begin{array}{r}15 \cdot 1 \\
13 \cdot 9 \\
11 \cdot 6 \\
67 \cdot 2 \\
25 \cdot 8 \\
22 \\
97 \cdot 9 \\
30 \cdot 7 \\
23 \cdot 7 \\
5 \cdot 1\end{array}$ & $\begin{array}{c}79 \cdot 7(41-139) \\
229 \cdot 9(157-325) \\
180.9(112-277) \\
184.4(153-220) \\
147.5(104-202) \\
113.7(111-221) \\
280 \cdot 0(248-315) \\
156 \cdot 6(115-208) \\
257 \cdot 4(197-330) \\
253.0(135-433)\end{array}$ \\
\hline Women & $\begin{array}{r}1 \\
2 \\
3 \\
4 \\
5 \\
6 \\
7 \\
8 \\
9 \\
10\end{array}$ & $\begin{array}{l}\text { West Groningen } \\
\text { IJmond } \\
\text { Zaanstreek } \\
\text { Amsterdam City } \\
\text { Rest of Amsterdam } \\
\text { Gooi and Vecht } \\
\text { Rijmond } \\
\text { South east South Holland } \\
\text { North Sealand } \\
\text { Flevoland }\end{array}$ & $\begin{array}{r}14 \\
6 \\
5 \\
29 \\
4 \\
6 \\
26 \\
5 \\
4 \\
1\end{array}$ & $\begin{array}{r}5 \cdot 7 \\
2 \cdot 4 \\
2 \cdot 0 \\
14 \cdot 2 \\
4 \cdot 3 \\
4 \cdot 5 \\
18 \cdot 6 \\
5 \cdot 3 \\
4 \cdot 1 \\
0 \cdot 6\end{array}$ & $\begin{array}{c}244 \cdot 3(134-410) \\
249 \cdot 3(91-543) \\
249 \cdot 6(81-583) \\
203 \cdot 9(137-293) \\
92 \cdot 8(25-238) \\
134 \cdot 4(49-293) \\
140 \cdot 0(91-205) \\
94 \cdot 6(31-221) \\
96 \cdot 7(26-248) \\
165 \cdot 0(2-918)\end{array}$ \\
\hline
\end{tabular}

Figure 2 Geographical pattern of death from pleural mesothelioma in men for 43 regions in the Netherlands by quartile, 1979-86. Numbers refer to selected regions shown in table 3.

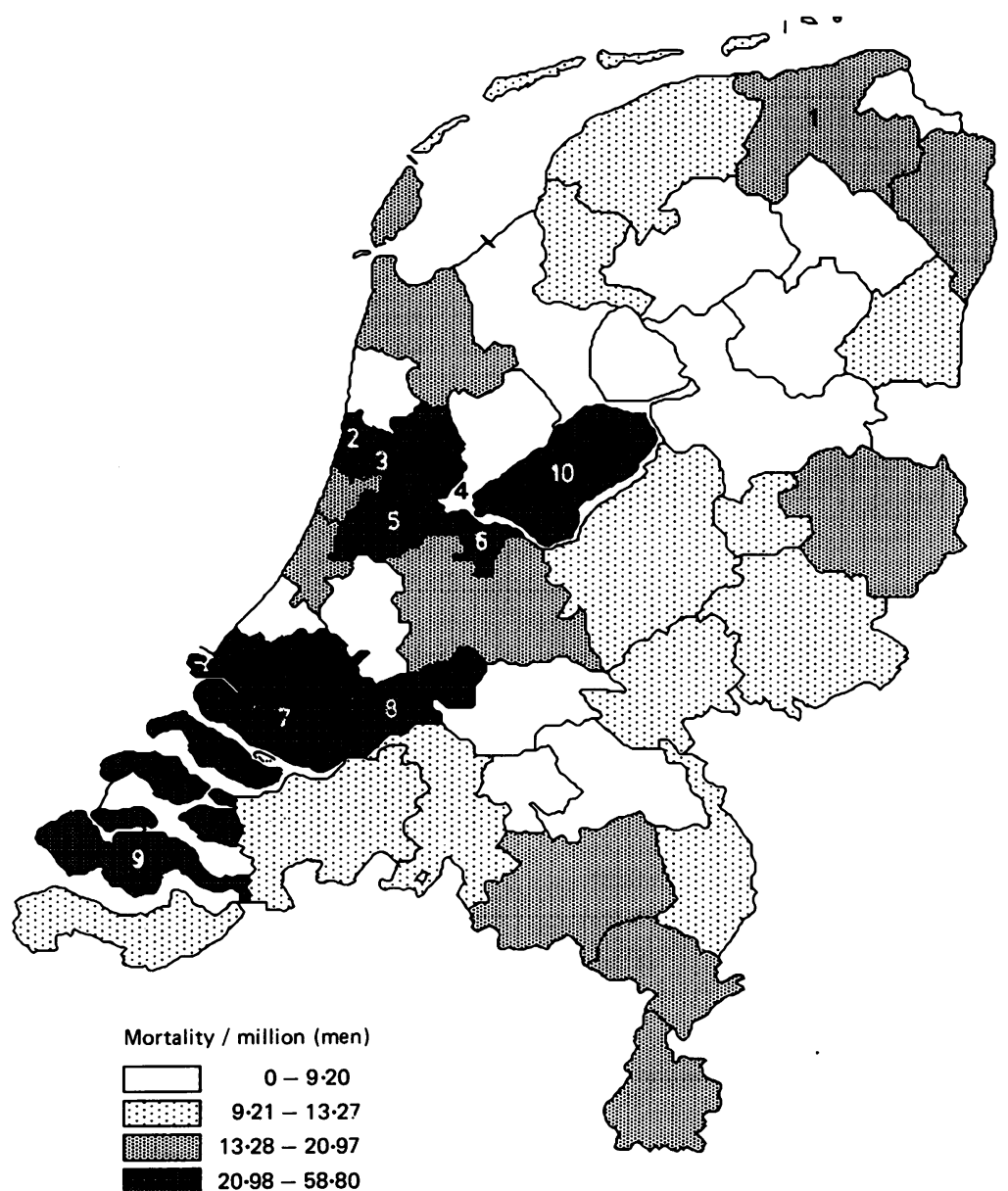


Figure 3 Geographical pattern for female pleural mesothelioma death for 43 regions in the Netherlands by quartile, 1979-86. Numbers refer to selected regions shown in table 3.

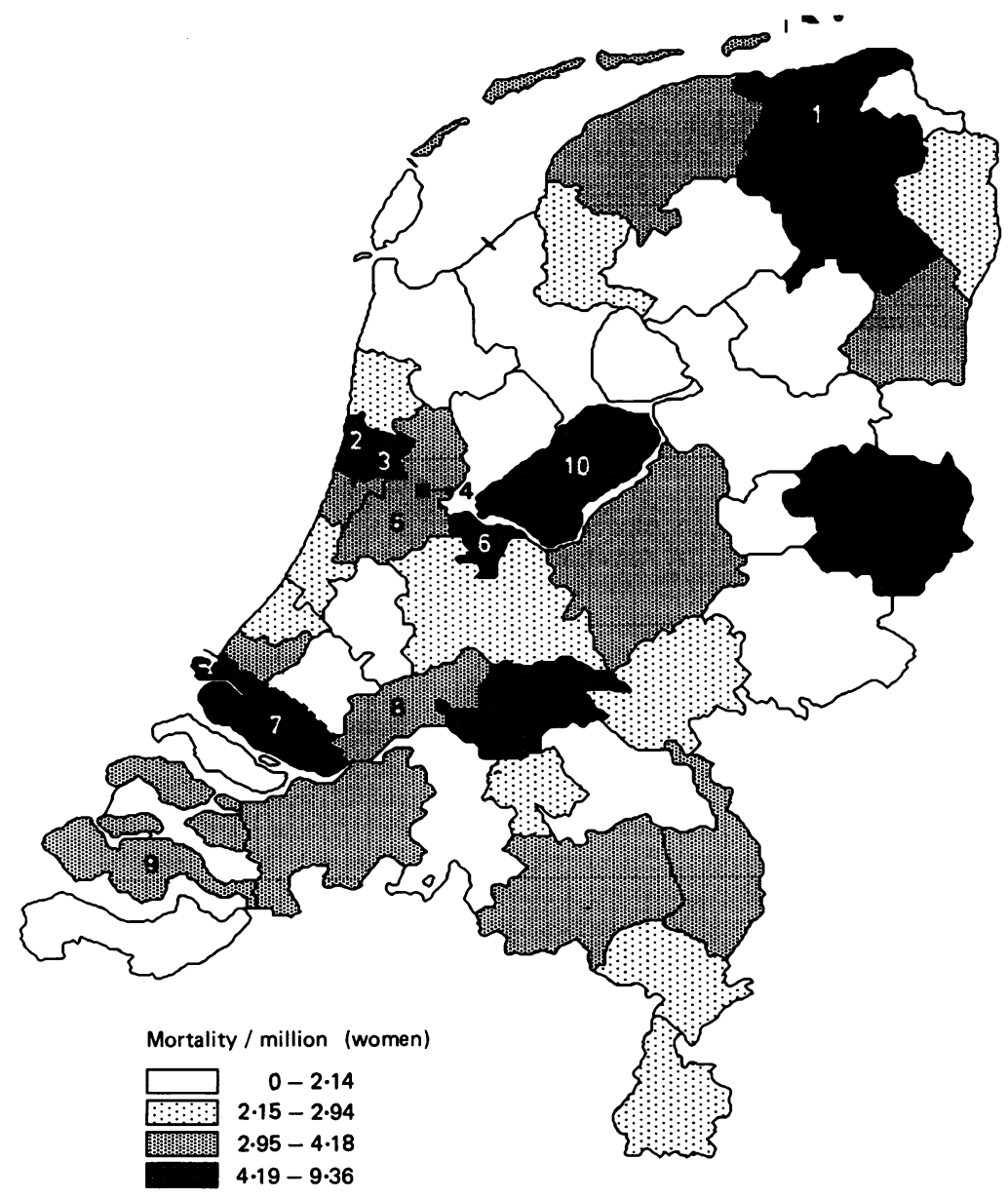

employed by shipyards and other heavy industries used asbestos for insulation and other technical purposes. ${ }^{17}$ In the other 34 Dutch areas no significant excess in pleural mortality from mesothelioma for men was experienced during the period of observation.

We investigated whether or not the distribution of SMRs over the regions showed a similar pattern for women. This did not seem to be the case. The only two Dutch regions where the pleural mortality from mesothelioma was significantly increased for women were the city of Amsterdam and the western Groningen region. In all the other areas SMRs did not reach statistical significance. Traditionally most Dutch wives are housewives and do not work in heavy industry. It is likely that the geographical patterns of pleural mesotheliomas for men and women visualise the differences in the occupational exposure of the sexes to asbestos. A high occupational exposure of men in the areas earlier mentioned does not necessarily imply an increased incidence of mesothelioma for women living in the same area. An explanation for the significant increase in mesotheliomas in women in western Groningen compared with other areas is not available.

Figures 2 and 3 show the death rates for pleural mesotheliomas over the period $1979-86$ by quartile for men and women. Mortality in men varies greatly. The clustering in the western areas of the Netherlands with shipbuilding and other heavy industries, is obvious. Mortality for men in the Rotterdam area was 59 per million, in North Sealand, 54 per million, in IJmond 48 per million and in Amsterdam 39 per million. In the southern and north eastern part of the country there was also some clustering up to 21 per million. For women regional mortality was much lower and did not exceed 10 per million. The highest rates of pleural mesothelioma were found in the 
province of Groningen in the north eastern part of the country, in small clusters in the middle of the country and the Rotterdam area, and also in the region of Twente in the middle east. In Twente a concentration of factories with much asbestos pollution and a factory producing asbestos cement products existed. Possibly the high exposure levels in these industries led to the increased risk of mesotheliomas for men and women.

The mesothelioma panel registered 100 new cases with a proven or probable diagnosis of pleural mesothelioma during 1986. An additional questionnaire to all Dutch pathological laboratories resulted in another 88 cases of mesothelioma of which 17 showed a peritoneal origin.

Thus the total number of histologically verified pleural mesotheliomas (morbidity) amounted to 171 in 1986, which is in reasonable agreement with the national mortality figure of 193 cases.

\section{Discussion}

Our study presents trends and geographical patterns in deaths from pleural mesothelioma in the Netherlands based on the ICD classification of pleural malignancies. This can lead to under or overestimations of the real number of pleural mesotheliomas. The pathological characterisation of mesotheliomas can be difficult and differences between a lower awareness in the sixties and the recently increased focus upon asbestos related diseases could lead to classification bias. Nevertheless, the comparison between numbers derived from the ICD and the results from the mesothelioma register, together with the expected age and sex related trends and geographical patterns demonstrate that misclassification of pleural mesotheliomas has not seriously influenced the outcomes. Pleural mesothelioma is particularly a disease of middle and old age resulting from exposure to asbestos early in the subjects' working history. The risk of mortality for women is low compared with men, and the mortality for men has shown a marked increase over the past 20 years. Jones et al reported a crude death rate from mesothelioma in Great Britain of 17.5 per million for men and 3.2 per million for women in $1983 .{ }^{6}$ In the United States the incidence of pleural mesothelioma for men and women amounted to 10.6 and 1.9 per million for the years 1973 to $1984 .{ }^{18}$ In Denmark the incidence of mesothelioma in the period 1978-80 reached $14 \cdot 7$ per million for men and 7.0 per million for women. ${ }^{9}$ In Western Australia, where crocidolite was mined and milled between 1943 and 1966, the age standardised incidence of mesotheliomas in 1980-82 was 66 per million for men and seven per million for women aged over $35 .^{19}$ In South Africa, Zwi et al reported an incidence of mesothelioma of 32.9 and 8.9 per million for men and women for the years 1976-84. ${ }^{7}$ Compared with these outcomes for selected industralised countries, the average Dutch death rates per million for pleural mesothelioma during 1979-87 are considerably lower than the figures for men and women from the countries producing and exporting asbestosnamely, South Africa and Western Australia, but two fold higher than the reference figures of the United States and the outcomes for men in Denmark. They resemble the results from Great Britain. Just as in Great Britain, the Netherlands have never had any asbestos mining and million corporations, but importation rose to 49400 tonnes of raw asbestos and 15300 tonnes of asbestos in finished products in 1976 (personal communication from the Centraal Bureau voor de Statistik). Asbestos cement products and floor coverings containing asbestos were produced in the Netherlands, along with the application of asbestos insulation in construction, shipbuilding, and other heavy industries. The widespread and increased occupational exposure to asbestos has clearly led to the relatively high incidence of pleural mesotheliomas. This is especially demonstrated by the sharp increase in mortality for men aged 65 to 74 , which is much higher than the rates in the United States, Denmark, and Great Britain. Numbers of deaths from pleural mesothelioma over time for women older than 54 are somewhat higher than in Great Britain and their moderate upward trend is comparable with the outcomes from other countries.

Concerning the geographical distribution of deaths from mesothelioma, Enterline and Henderson compared sex related pleural mesotheliomas between 1968 and 1981 for the 51 American states. ${ }^{11}$ Clusters of mesothelioma on a state level did not exceed 3.38 per million for men and 1.67 per million for women. The quartile with the highest death rates in the Netherlands demonstrates regional clusters of between 21 and 59 per million for men. This can be partly explained by the fact that the American states are many times larger than the Dutch regions and as a result possibly existing clusters are diluted in the United States. It is also possible that the strong clustering for men in some Dutch regions is due to the high occupational exposure in the industralised areas with many harbours and shipyards. For women the American studies showed clusters of up to 1.77 per million on a state level compared to a highest quartile in the Netherlands of between 4.2 and 9.4 per million. The reason for these differences in mortality for women between the Netherlands and the United States is less clear. It is again possible that because of the large geographical regions in the United States local clusters of increased mortality cannot be detected; but perhaps the differences reflect variations in environmental exposure to asbestos for women. On a county level in Great Britain, crude death rates for all mesotheliomas amounted to 30.5 per million for men in regions with shipbuilding 
and repair industries and 11.0 for women in Lancashire. ${ }^{6}$ The clustering of pleural mesotheliomas for men in certain Dutch regions seems to be more pronounced than in Great Britain. The levels of mortality in women are comparable between The Netherlands and Great Britain.

Because of legislation in 1977 (the asbestos decrees) which led to a prohibition of the use of crocidolite and a threshold limit value for the other types of asbestos and a higher general awareness of the risks to health associated with asbestos, the import of raw asbestos declined from 49400 tonnes in 1976 to 5600 tonnes in 1985 (personal communication from the Centraal Bureau voor de Statistiek). It is difficult to predict the future trend of mortality from pleural mesothelioma in the Netherlands. Assuming that the mean latency time for mesotheliomas after exposure to asbestos is about 35 years, we expect that the increased use combined with the increased exposure to asbestos up to 1976 will not result in a decline in asbestos related mesotheliomas until 2010. By applying techniques of linear regression to the overall sex related mortality shown in fig 1 , mortality rates to the year 2010 was projected. This resulted in an extrapolated overall mortality from mesothelioma of about 50 per million for men and 5.8 per million for women. Combined with the prognosis about the growth of the total population provided by the Central Bureau of Statistics, this produced a crude number of 397 deaths from mesothelioma in men and 48 deaths in women in 2010 . These projections are highly speculative, because exact information about the variations in exposure with time is lacking. We can, however, expect the mortality from mesothelioma to increase, especially in men, as their exposure to asbestos during the 1950 s and 60 s in the insulation industry was high and occupational hygiene standards were relatively poor. Altogether the data presented show that asbestos related mortality from mesothelioma imposes a serious health problem to Dutch society, and it is feasible that the mortality from pleural mesothelioma will increase in the near future. It will be another 20 years before a significant decrease in mortality from mesothelioma in the Netherlands can be expected.
We thank the Central Bureau of Statistics and the Medical Information Centre of the University of Limburg for providing the mortality figures on which this paper is based.

Requests for reprints to: Jan M M Meijers, Department of Occupation and Environmental Health and Toxicology, PO Box 616, 6200 MD Maastricht, the Netherlands.

1 Wagner JC, Sleggs CA, Marchand P. Diffuse pleural mesothelioma and asbestos exposure in the North Western Cape province. Brit J Ind Med 1960;17:260-71.

2 McDonald JC. Health implications of environmental exposure to asbestos. Environ Health Perspect 1985;62:319-28.

3 Churg A. Malignant mesothelioma in British Columbia in 1982. Cancer 1985;55:672-4.

4 Scataridge JC, Stitik FP. Induction of thoracic malignancy in inorganic dust pneumoconiosis. J Thorac Imaging 1988;3: 67-79.

5 Selikoff IF, Lee DHK. Asbestos and disease. New York: Academic Press, 1978.

6 Jones RD, Smith DM, Thomas PG. Mesothelioma in Great Britain in 1968-1983. Scand J Work Environ Health 1988; 14:145-52.

7 Zwi AB, Reid G, Landau SP, Kielkowski D, Sitas F, Becklake MR. Mesothelioma in South Africa, 1976-84: Incidence and case characteristics. Int J Epidemiol 1989;18:320-9.

8 Ferguson DA, Berry G, Jelihovsky $T$, et al. The Australian mesothelioma surveillance program 1979-1985. Med J Aust 1987;147:166-72.

9 Andersson $\mathrm{M}$, Olsen $\mathrm{JH}$. Trend and distribution of mesothelioma in Denmark. Br J Cancer 1985;51:699-705.

10 Minder CE, Vader JP. Malignant pleural mesothelioma among Swiss furniture workers. Scand $J$ Work Environ Health 1988;14:252-6.

11 Enterline PE, Henderson VL. Geographic patterns of pleural mesothelioma deaths in the United States, 1968-81. J Natl Cancer Inst 1987;79:31-7.

12 Newhouse $M$. Epidemiology of asbestos-related tumours. Seminars in Oncology 1981;8:250-7.

13 Gardner MJ, Acheson ED, Winter PD. Mortality from mesothelioma of the pleura during 1968-78 in England and Wales. Br J Cancer 1982;46:81-8.

14 Archer VE, Rom WN. Trends in mortality of diffuse malignant mesothelioma of pleura. Lancet 1983;ii:112-3.

15 Planteydt HT. Netherlands Mesothelioma Register. Ann NY Acad Sci 1979;330:467-71.

16 Breslow NE, Day NE. Statistical methods in cancer research. Vol 2. The design and analysis of cohort studies. Lyon: International Agency for Research on Cancer, 1987.

17 Stumphius J. Epidemiology of mesothelioma on Walcheren Island. Br J Ind Med 1971;28:59-66.

18 Connelly RR, Spirtas R, Myers MH, Percy CL, Fraumeni JF. Demographic patterns for mesothelioma in the United States. $J$ Natl Cancer Inst 1987;78:1053-60.

19 Armstrong BK, Musk AW, Baker JE, et al. Epidemiology of malignant mesothelioma in Western Australia. Med $J$ Aust 1984;141:86-8.

Accepted 3 April 1990 